\title{
Lead exposure among the general population of Duhok governorate, Kurdistan region, Iraq
}

\author{
A.H. Al-Dosky, D.J. Al-Timimi' and S.A. Al-Dabbag ${ }^{2}$
}

$$
\text { علي الدسقي، ضياء التميمي، صميم الدباغ عامة السكان في محافظة دهوك، إقليم كردستان، العراق }
$$

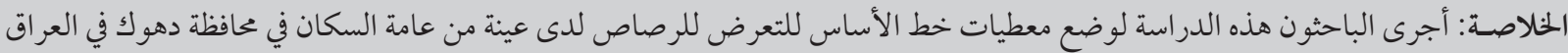

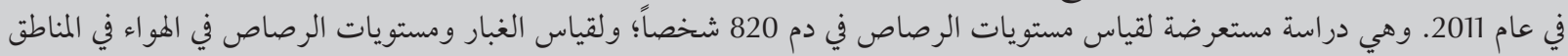

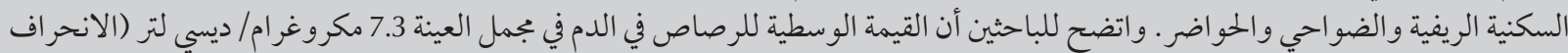

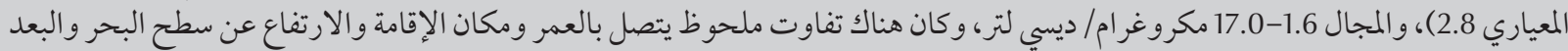

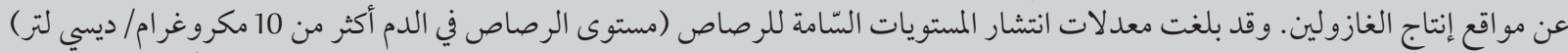

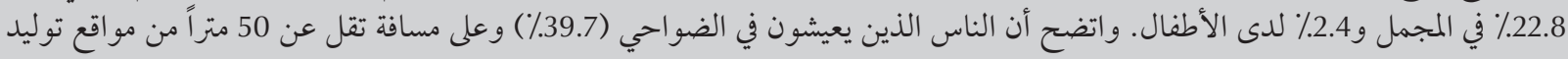

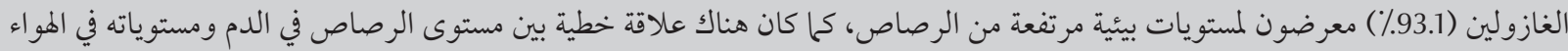

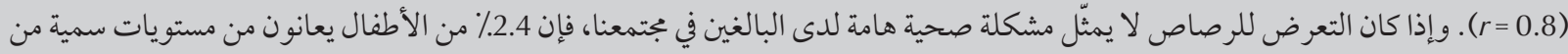

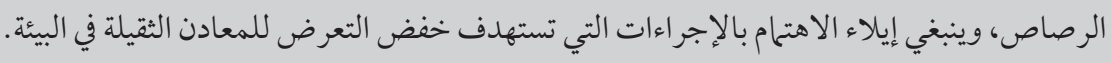

ABSTRACT This study was carried out to establish baseline data on lead exposure in a sample of the general population from Duhok governorate, Iraq in 2011. A cross-sectional study was made of blood lead levels of 820 individuals and of dust and of air lead levels in urban, suburban and rural residential areas. Mean blood lead $(\mathrm{BPb})$ value in the overall sample was 7.3 (SD 2.8) $\mu \mathrm{g} / \mathrm{dL}$, range 1.6-17.0 $\mu \mathrm{g} / \mathrm{dL}$; significant differences were found with respect to age, area of residence, altitude and distance from a gasoline generator. The prevalence of toxic levels of lead (BPb $>10 \mu \mathrm{g} / \mathrm{dL}$ ) was $22.8 \%$ overall and $2.4 \%$ in children. People living in suburban areas $(39.7 \%)$ and $<50 \mathrm{~m}$ from a gasoline generator (93.1\%) were exposed to high environmental lead levels. A linear relationship was found between $\mathrm{BPb}$ and air lead levels $(r=0.8)$. While lead exposure does not constitute a great health problem for adults in our community, $2.4 \%$ of the children had toxic lead levels and measures to reduce exposure to environmental heavy metals should be considered.

Exposition au plomb dans la population générale du gouvernorat de Duhok, dans la région du Kurdistan (Iraq)

RÉSUMÉ La présente étude a été menée pour établir une base de données sur l'exposition au plomb d'un échantillon de la population générale du Gouvernorat de Duhok (Iraq) en 2011. Une étude transversale a été réalisée sur la concentration sanguine de plomb chez 820 personnes ainsi que sur les taux de poussière et de plomb dans l'air des zones résidentielles urbaines, suburbaines et rurales. La concentration moyenne de plomb dans le sang de l'échantillon global était de 7,3 $\mu \mathrm{g} / \mathrm{dl}$ (E.T. 2,8 ; extrêmes 1,6-17,0 $\mu \mathrm{g} / \mathrm{dl}$ ) ; des différences significatives ont été retrouvées en fonction de l'âge, du lieu d'habitation, de l'altitude et de la distance par rapport à un groupe électrogène à essence. La prévalence de niveaux toxiques de plomb (concentration moyenne de plomb dans le sang $>10 \mu \mathrm{g} / \mathrm{dl}$ ) était de $22,8 \%$ dans l'ensemble de l'échantillon et de 2,4 \% chez les enfants. Les personnes vivant dans des zones suburbaines $(39,7 \%$ ) et à moins de $50 \mathrm{~m}$ d'un groupe électrogène à essence $(93,1 \%$ ) étaient exposées à des niveaux élevés de plomb dans l'environnement. Une relation linéaire a été retrouvée entre la concentration moyenne de plomb dans le sang et les niveaux de plomb dans l'air $(r=0,8)$. Alors que l'exposition au plomb ne constitue pas un problème de santé majeur pour les adultes de notre communauté, 2,4\% des enfants présentaient des concentrations de plomb toxiques. Des mesures de réduction de cette exposition aux métaux lourds dans l'environnement doivent être envisagées.

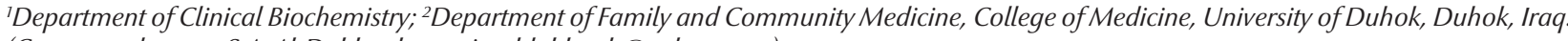
(Correspondence to S.A.Al-Dabbagh: samimaldabbagh@yahoo.com).

Received: 29/08/11; accepted: 02/11/11 


\section{Introduction}

Exposure to low doses of lead is particularly harmful to children, whose neurological development may be persistently and irreversibly affected [1-3]. Exposure to lead causes a number of diseases in later age groups, including mild mental retardation, as shown by loss of IQ points, as well as increased blood pressure, anaemia and gastrointestinal effects. Several other disease outcomes have been associated with exposure to lead $[4,5]$. The only efficacious method of avoiding these toxic effects is to control the population's exposure to lead by eradicating its sources, which are not always obvious. Hence it is essential to know the level of exposure of the population so that the necessary control measures can be established.

In Iraq, most studies on lead exposure have been conducted in exposure risk groups [6]. However, considering that there are still many gasoline power generators and vehicles using leaded petrol in the country, it is possible that high lead levels exist in the general population living in areas of heavy traffic and high emission of lead into the atmosphere. Therefore, this study was carried out to establish baseline data on blood and environmental lead levels in a sample of the general population from the Duhok governorate area.

\section{Methods}

\section{Setting and sample}

A cross-sectional study design was conducted on 820 individuals who were not occupationally exposed to lead. They were apparently healthy individuals of both sexes with an age range from 1 month to 64 years. All had no history of chronic illness or of personal or family history of lead exposure.

The sample size was calculated according to the World Health Organization formula to be around 767 [7]. Individuals living in 3 distinct living areas (urban, suburban and rural) were included in this study. The urban areas were in Duhok city, the main urban area in the centre of Duhok governorate. The city is located in a valley between 2 mountains and areas were chosen at different altitudes in the valley: low $(540-<560 \mathrm{~m})$, moderate $(560-<630 \mathrm{~m})$, and high $(>630$ $\mathrm{m})$. The suburban areas chosen were districts $60 \mathrm{~km}$ west of Duhok, 100 $\mathrm{km}$ east of Duhok and $70 \mathrm{~km}$ north Duhok. The rural areas chosen were 5 villages situated in the districts of Duhok governorate where there were no municipality and no industrial sources of lead pollution. Among the individuals selected, 420 were urban living in different parts of Duhok city, 300 were living in suburban areas and 100 were living in rural areas. Urban samples were collected from Azadi main secondary care hospital and the primary health centre in Duhok, suburban samples were collected from the local hospital while rural samples were collected directly from in the village main hall.

\section{Data collection}

A pre-tested questionnaire was designed to obtain information on age, sex, residence, cigarette smoking and current occupation.

\section{Samples}

Since blood lead estimation is easily affected by contamination suitable precautions were taken to avoid any contamination and a trace-element-free technique was used during the handling and analysis of blood samples. Venous blood samples $(5 \mathrm{~mL})$ were withdrawn from each individual under study and transferred to EDTA tubes for the estimation of blood lead level.

For determination of environmental dust lead levels roadside dust samples were collected from different residential areas (urban, suburban and rural) using methods specified by the manufacturer of the test kit.

For determination of environment air lead levels roadside air samples were collected from the same urban and rural areas investigated. A low flow-rate sampler with maximum flow rate of 6 $\mathrm{m}^{2} / 24$ hours was used. This sampler was equipped with a pump, a counter, a $3.7 \mathrm{~cm}$ disk holder and fitted with glass fibre filter (Whitman GF/A). The collection time was 72 hours in the urban areas and 144 hours in the rural areas.

Verbal consent for participation and approval to supply blood samples for testing was obtained from the parents of the children and from the adults, after the nature of the study had been explained to them. The study protocol was approved by the local scientific and ethical committees.

\section{Analysis}

Blood lead was analysed by flame atomic absorption spectrophotometer (Perkin Elmer) using a standardized procedure published by the company. Radiation source absorbance was measured at a wavelength of $283 \mathrm{~nm}$, using a band pass of $0.7 \mathrm{~nm}$. Briefly EDTA-blood was precipitated with $20 \%$ trichloroacetic acid (TCA) solution. The supernatant solution was aspirated directly to the spectrophotometer and the samples were run in batches using standard lead solution of 10,25 and $50 \mu \mathrm{g} / \mathrm{dL}$ to correct the sensitivity of the instrument. A reagent blank was prepared by mixing an equal volume of $20 \%$ TCA with deionized water. The blank gave a reading of $1 \mu \mathrm{g} /$ $\mathrm{dL}$ and this value was subtracted from the reading of the samples examined. A pooled normal blood was run with every batch and gave a reading of $12 \mu \mathrm{g} /$ dL. Serial replication of aliquots from a pooled blood sample and an internal control standard were used to check the precision and accuracy of the analytical method. The coefficient of variation for lead in pooled blood samples was 3.5\% $(n=30)$. Values for the internal control 
standards (Radian Corporation) were calculated between every 10 samples in the rack of samples with each new batch. Samples which did not differ by more than $2 \%$ of the standard value were considered acceptable. All samples were analysed in triplicate and results referred to the standard curve previously prepared.

The dust lead levels in each area were estimate using a standard lead test kit (Abbott Laboratories). This test utilizes a patented leach method for testing and gives semi-quantitative results which indicate the approximate lead release in samples. After the comparison of the resultant colour produced, the concentration of lead is shown into parts per million (ppm).

For the air samples, lead from the Whitman glass fibre filter was extracted with $5 \%$ nitric acid. Similar to the blood samples, the lead concentration was estimated by direct aspiration into the flame of the atomic absorption spectrophotometer. The air lead content was calculated from the American Society for Testing Materials formula [8].

\section{Assessment of lead exposure}

The highest values for toxic levels of $\mathrm{BPb}$ lead according to the recommendations of the Centers for Disease Control and Prevention [9] were selected as the cutoffs for this study: $>10 \mu \mathrm{g} / \mathrm{dL}$ in children and $>25 \mu \mathrm{g} / \mathrm{dL}$ in adults. Dust lead levels $>5$ ppm was considered as the cutoff value for low level of lead exposure whereas a level of $<25 \mathrm{ppm}$ indicated high level of lead exposure.

\section{Statistical analysis}

Data were translated into a computerized database structure. Statistical analyses were computer assisted using SPSS, version 13. The correlations between blood lead level (BPb) and air lead level was estimated by linear regression analysis.

\section{Results}

\section{Blood lead level}

The mean $\mathrm{BPb}$ value in the total sample was $7.3 \mu \mathrm{g} / \mathrm{dL}$ [standard deviation (SD) $2.8 \mu \mathrm{g} / \mathrm{dL}$ ], range 1.6 to $17.0 \mu \mathrm{g} /$ $\mathrm{dL}$. The mean $\mathrm{BPb}$ concentration in adults (ages 17-64 years) was 8.6 (SD 3.3) $\mu \mathrm{g} / \mathrm{dL}$ and in children (ages $>1-16$ years) was $5.3(\mathrm{SE} 1.9) \mu \mathrm{g} / \mathrm{dL}$, a difference which was statistically significant $(P<0.01)$. Mean BPb levels of males $[8.6($ SD 3.5$) \mu \mathrm{g} / \mathrm{dL}]$ were significantly higher than those of females $[4.7$ (SD 1.4) $\mu \mathrm{g} / \mathrm{dL}](P<0.01)$. The mean $\mathrm{BPb}$ concentration in those living in rural areas $[4.2(\mathrm{SD} 1.2) \mu \mathrm{g} / \mathrm{dL}]$ was significantly lower compared with the urban and suburban groups, who had mean levels of $6.9(\mathrm{SD} 3.0) \mu \mathrm{g} / \mathrm{dL}$ and 9.1 $(\mathrm{SD} 3.2) \mu \mathrm{g} / \mathrm{dL}$ respectively $(P<0.001$ for all) (Table 1).

Comparing the mean $\mathrm{BPb}$ level of urban males $(n=320)$ and females ( $n$ $=100$ ) showed higher values for males

\begin{tabular}{|c|c|c|c|c|}
\hline \multirow[t]{2}{*}{ Variable } & \multirow{2}{*}{$\begin{array}{l}\text { Total } \\
\text { No. }\end{array}$} & \multicolumn{2}{|c|}{ Blood lead concentration ( $\mu \mathrm{g} / \mathrm{dL})$} & \multirow[t]{2}{*}{$P$-value ${ }^{a}$} \\
\hline & & Mean (SD) & Range & \\
\hline Age of children (years) & & & & $<0.001^{\mathrm{b}}$ \\
\hline$<1$ & 22 & $3.3(0.7)$ & $1.6-4.4$ & \\
\hline$<5$ & 46 & $4.3(0.5)$ & $1.8-5.0$ & \\
\hline $5-9$ & 66 & $5.5(1.4)$ & $2.1-7.8$ & \\
\hline $10-16$ & 73 & $6.2(2.4)$ & $2.5-10.1$ & \\
\hline All & 207 & $5.3(1.9)$ & $1.6-10.1$ & \\
\hline Age of adults (years) & & & & $<0.001$ \\
\hline $17-9$ & 349 & $7.7(2.9)$ & $3.3-13.0$ & \\
\hline $30-39$ & 168 & $9.2(3.2)$ & $3.8-14.9$ & \\
\hline $40+$ & 96 & $11.1(2.9)$ & $5.8-17.0$ & \\
\hline All & 613 & $8.6(3.3)$ & $3.3-17.0$ & \\
\hline Sex & & & & $<0.001$ \\
\hline Male & 541 & $8.6(3.5)$ & $2.7-17.0$ & \\
\hline Female & 279 & $4.7(1.4)$ & $1.6-9.4$ & \\
\hline Residence area & & & & $<0.001$ \\
\hline Urban & 420 & $6.9(3.0)$ & $1.6-15.0$ & \\
\hline Suburban & 300 & $9.1(3.2)$ & $4.0-17.0$ & \\
\hline Rural & 100 & $4.2(1.2)$ & $2.1-7.6$ & \\
\hline Total & 820 & $7.3(2.8)$ & $1.6-17.0$ & \\
\hline
\end{tabular}

${ }^{a}$ Analysis of variance; ${ }^{b}$ Age group $<1$ year versus $10-16$ years.

$S D=$ standard deviation . 
$[7.6(\mathrm{SD} 3.7) \mu \mathrm{g} / \mathrm{dL}]$ than females $[4.4$ $(\mathrm{SD} 0.6) \mu \mathrm{g} / \mathrm{dL})](P<0.001)$. However, the difference was smaller and non-significant comparing rural males $(n=54)$ and rural females $(n=46)[4.5$ (SD 1.8) $\mu \mathrm{g} / \mathrm{dL}$ versus 3.9 (SD 0.5) $\mu \mathrm{g} /$ dL] $(P>0.05)$.

Current guidelines for lead poisoning consider cut-offs for toxic levels when BPb levels are $>10 \mu \mathrm{g} / \mathrm{dL}$ for a child and $>25 \mu \mathrm{g} / \mathrm{dL}$ for an adult. We found $5 / 207$ children $(2.4 \%$ ) had BPb level $>10 \mu \mathrm{g} / \mathrm{dL}$, whereas 182/613 adults (29.7\%) had BPb level 10-25 $\mu \mathrm{g} / \mathrm{dL}$. Therefore out of the total tested, 187 (22.8\%) individuals had toxic $\mathrm{BPb}$ levels > $10.0 \mu \mathrm{g} / \mathrm{dL}$ (Table 2).

$\mathrm{BPb}$ levels according to distance in which participants living from a gasoline generator and altitude are shown in Table 3. The mean $\mathrm{BPb}$ levels of individuals living in areas 100-149, 50-99 and > $50 \mathrm{~m}$ distance from gasoline generators were 3.3, 6.8 and $9.6 \mu \mathrm{g} / \mathrm{dL}$ respectively $(P<0.001$ for all). BPb levels were also significantly higher in individuals of living at low altitudes compared with moderate or high altitude levels $(P<$ 0.001).

\section{Dust lead level}

Table 4 presents the distribution of the study sample according to median dust lead values found in the areas where they lived. The highest proportion of people living in areas with lead level in the range $25-50 \mathrm{ppm}$ was found in those living in suburban areas (39.7\%), at low altitudes $(62.8 \%)$ and $<50 \mathrm{~m}$ from a gasoline generator (93.1\%).

\section{Air lead level}

Table 5 shows the mean lead levels in environmental air. Mean lead levels were significantly higher in urban areas than suburban and rural areas $(P<$ 0.001). The mean blood lead levels of participants were positively correlated with mean lead levels in air $(r=0.8, P$ $<0.01)$.

\section{Discussion}

The $\mathrm{BPb}$ level is commonly used as an indicator of lead exposure in humans [10]. Among the individuals in the present study, mean $\mathrm{BPb}$ concentration in adults was $8.6 \mu \mathrm{g} / \mathrm{dL}$ and in children was $5.3 \mu \mathrm{g} / \mathrm{dL}$. The results suggest that, overall, individuals in our study had $\mathrm{BPb}$ levels within the acceptable limit reported by others $(7.3 \mu \mathrm{g} / \mathrm{dL})$ [11]. Previous studies in other parts of Iraq found higher BPb levels in the population $[12,13]$. For example, a study conducted on 629 elementaryschool children in Baghdad found a mean BPb level of $13.9 \mu \mathrm{g} / \mathrm{dL}$ [14]; this value was higher than ours, probably due to the origin of their samples, which were taken mainly from the centre of the city. Furthermore, several studies on children in the Eastern Mediterranean region (EMR) indicated high levels of lead exposure. For example, an investigation of environmental lead concentrations in Cairo indicated that the $\mathrm{BPb}$ levels of children ranged from $14.4 \mu \mathrm{g} / \mathrm{dL}$ for those $<1$ year old to 10.8 $\mu \mathrm{g} / \mathrm{dL}$ for those aged 5-6 years old, and that approximately $64 \%$ of children had $\mathrm{BPb}$ levels $>10 \mu \mathrm{g} / \mathrm{dL}$. Similar findings have been reported from Pakistan and Saudi Arabia, as well as other countries in the EMR [15]. However, our results, in comparison, reflected a lower level of exposure, probably due to the geographical nature of the residential areas, the low number of vehicles, no industrial emissions and low occupational exposure [16].

With respect to BPb levels, our results overall showed higher values in urban individuals living near gasoline generators or at low altitudes. Other studies concur with this observation of higher values in urban areas with greater atmospheric contamination by

\begin{tabular}{|c|c|c|c|c|c|c|c|}
\hline \multirow[t]{3}{*}{ Age (years) } & \multirow{3}{*}{$\begin{array}{l}\text { Total } \\
\text { No. }\end{array}$} & \multicolumn{6}{|c|}{ Blood lead concentration $(\mu \mathrm{g} / \mathrm{dL})$} \\
\hline & & \multicolumn{2}{|c|}{$<5.0$} & \multicolumn{2}{|c|}{ 5-10 } & \multicolumn{2}{|c|}{$>10-25$} \\
\hline & & No. & $\%$ & No. & $\%$ & No. & $\%$ \\
\hline \multicolumn{8}{|l|}{ Children } \\
\hline$<1$ & 22 & 22 & 100.0 & 0 & 0.0 & 0 & 0.0 \\
\hline$<5$ & 46 & 36 & 78.3 & 10 & 21.7 & 0 & 0.0 \\
\hline $5-9$ & 66 & 36 & 54.5 & 30 & 45.5 & 0 & 0.0 \\
\hline $10-16$ & 73 & 20 & 27.4 & 48 & 65.8 & 5 & 6.8 \\
\hline All & 207 & 114 & 55.1 & 88 & 42.5 & 5 & 2.4 \\
\hline \multicolumn{8}{|l|}{ Adults } \\
\hline $17-29$ & 349 & 89 & 25.5 & 172 & 49.3 & 88 & 25.2 \\
\hline 30-39 & 168 & 17 & 10.1 & 93 & 55.4 & 58 & 34.5 \\
\hline $40+$ & 96 & 0 & 0.0 & 60 & 62.5 & 36 & 37.5 \\
\hline All & 613 & 106 & 17.3 & 325 & 53.0 & 182 & 29.7 \\
\hline Total & 820 & 220 & 26.8 & 413 & 50.4 & 187 & 22.8 \\
\hline
\end{tabular}




\begin{tabular}{|c|c|c|c|c|}
\hline \multirow[t]{2}{*}{ Variable } & \multirow{2}{*}{$\begin{array}{l}\text { Total } \\
\text { No. }\end{array}$} & \multicolumn{2}{|c|}{ Blood lead concentration $(\mu \mathrm{g} / \mathrm{dL})$} & \multirow[t]{2}{*}{$P$-value ${ }^{a}$} \\
\hline & & Mean (SD) & Range & \\
\hline \multicolumn{5}{|c|}{ Distance from gasoline generator (m) } \\
\hline$<50$ & 158 & $9.8(3.5)$ & $4.0-15.0$ & \multirow{3}{*}{$<0.001$} \\
\hline $50-99$ & 140 & $6.8(1.5)$ & $2.7-12.7$ & \\
\hline 100-149 & 122 & $3.3(1.4)$ & 1.6-11.8 & \\
\hline \multicolumn{5}{|l|}{ Altitude } \\
\hline Low $(540->560 \mathrm{~m})$ & 163 & $9.1(4.4)$ & $3.7-15.0$ & \multirow{3}{*}{$<0.001$} \\
\hline Moderate $(560->630 \mathrm{~m})$ & 189 & $6.3(2.2)$ & $2.3-11.8$ & \\
\hline High over $(\geq 630 \mathrm{~m})$ & 68 & $3.3(1.9)$ & $1.6-7.6$ & \\
\hline
\end{tabular}

${ }^{a}$ Analysis of variance.

$S D=$ standard deviation .

\begin{tabular}{|c|c|c|c|c|c|c|c|c|c|c|}
\hline \multirow[t]{3}{*}{ Variable } & \multirow{3}{*}{$\begin{array}{c}\text { Total } \\
\text { No. }\end{array}$} & \multicolumn{9}{|c|}{ Dust lead concentration (ppm) } \\
\hline & & \multicolumn{2}{|c|}{$1-5$} & \multicolumn{2}{|c|}{$>5-10$} & \multicolumn{2}{|c|}{$>10-25$} & \multicolumn{2}{|c|}{$>25-50$} & \multirow[t]{2}{*}{ Median $^{\mathrm{a}}$} \\
\hline & & No. & $\%$ & No. & $\%$ & No. & $\%$ & No. & $\%$ & \\
\hline \multicolumn{11}{|c|}{ Residence area } \\
\hline Urban & 420 & 9 & 2.1 & 156 & 37.1 & 153 & 36.4 & 102 & 24.0 & $10-25$ \\
\hline Suburban & 300 & 0 & 0.0 & 27 & 9.0 & 154 & 51.3 & 119 & 39.7 & $10-25$ \\
\hline Rural & 100 & 18 & 18.0 & 55 & 55.0 & 27 & 27.0 & 0 & 0.0 & $5-10$ \\
\hline \multicolumn{11}{|c|}{ Distance from gasoline generator (m) } \\
\hline$<50$ & 158 & 0 & 0.0 & 0 & 0.0 & 11 & 7.0 & 147 & 93.0 & $25-50$ \\
\hline 50-99 & 140 & 0 & 0.0 & 0 & 0.0 & 47 & 33.6 & 93 & 66.4 & $25-50$ \\
\hline 100-149 & 122 & 0 & 0.0 & 6 & 4.9 & 113 & 92.6 & 3 & 2.5 & $10-25$ \\
\hline \multicolumn{11}{|l|}{ Altitude } \\
\hline Low & 317 & 0 & 0.0 & 37 & 11.7 & 81 & 25.6 & 199 & 62.8 & $25-50$ \\
\hline Moderate & 369 & 3 & 0.8 & 82 & 22.2 & 109 & 29.5 & 175 & 47.5 & $10-25$ \\
\hline High & 134 & 7 & 5.2 & 34 & 25.4 & 90 & 67.2 & 3 & 2.2 & $10-25$ \\
\hline
\end{tabular}

${ }^{a} \mathrm{P}<0.01$, Kruskal-Wallis: urban and suburban versus rural; distance from gasoline generators $<50 \mathrm{~m}$ and $50-99 \mathrm{~m}$ versus $100-149 \mathrm{~m}$; low and moderate altitude versus high altitude.

\begin{tabular}{lccc}
\hline \multicolumn{4}{l}{ Table 5 Mean lead levels in air of the urban, suburban and rural residential areas } \\
\hline Area & Total & Air lead concentration $\left(\mu \mathrm{g} / \mathbf{m}^{3}\right)$ \\
& No. & Mean $(\mathrm{SD})$ & Range \\
Urban & 34 & $3.80(0.51)$ & $1.30-7.02$ \\
Suburban & 2 & $2.29(0.24)$ & $2.04-2.52$ \\
Rural & 4 & $0.44(0.06)$ & $0.37-0.55$ \\
\hline
\end{tabular}

$S D=$ standard deviation .

the metal [17], and in crowded areas in which exposure to lead is higher owing to the greater number of gasoline generators and vehicles. The results obtained for prevalence of intoxication were also similar, since a greater prevalence was observed in individuals residing in downtown areas and those living near gasoline generators.

Regarding age and sex, we found a tendency towards increased BPb levels with higher age, probably due to higher exposure to lead from the contaminated atmosphere owing to increased outdoor activity. A statistically significant difference was found in the mean lead levels of males and females. Other authors have also demonstrated lower lead levels in females, below the toxic limit [18]. In fact, none of the females in our series had $\mathrm{BPb}$ levels within the elevated range $(>10 \mu \mathrm{g} / \mathrm{dL})$. However, large numbers of males had $\mathrm{BPb}$ values $>10 \mu \mathrm{g} / \mathrm{dL}$. This could be also attributed to increased outdoor activity and to cigarettes smoking (none of the females in this study reported being a cigarette smoker).

Blood lead level determination is the method currently recommended 
for lead exposure assessment [19]. The use of dust and air lead assessment has been previously recommended as additional markers for lead source and exposure [20]. We found a tendency towards increased $\mathrm{BPb}$ values with increasing level of exposure indicated by dust and air levels. In our sample, 57.8\% of individuals were living in areas with dust lead levels 25-50 ppm and most of them in urban and suburban areas of high air lead levels.

We conclude from our results that lead exposure does not constitute a great health problem for the adult population of our community, since average blood lead levels were below toxic levels and the prevalence of intoxication was similar to that reported in other studies. Nevertheless, $2.4 \%$ of the children had toxic levels of lead and measures to reduce exposure to environmental heavy metals should be considered, especially in urban areas where children are particularly at risk.

\section{References}

1. American Academy of Pediatrics. Committee on Environmental Hazards: Committee on Accident And Poison Prevention. Statement on childhood lead poisoning. Pediatrics, 1987, 79:457-465.

2. Bellinger D. Lead neurotoxicity and socioeconomic status: conceptual and analytic issues. Neurotoxicology, 2008, 29(5):828-832.

3. Jones RL et al. Trends in blood lead levels and blood lead testing among US children aged 1 to 5 years, 1988-2004. Pediatrics, 2009, 123:e376-e385.

4. Schwartz J. Low-level lead exposure and children's IQ: a metaanalysis and search for a threshold. Environmental Research, 1994, 65:42-55.

5. Koller K et al. Recent developments in low-level lead exposure and intellectual impairment in children. Environmental Health Perspectives, 2004, 112:987-994.

6. Al-Timimi DJ. The adverse health effects of direct and indirect exposure to lead among battery factory workers. Journal of Community Medicine, Baghdad, 1990, 3(20):103-110.

7. Introduction to basic epidemiology and principles of statistics for tropical disease control. Geneva, World Health Organization, 2002.

8. Toxic materials in the atmosphere: sampling and analysis. A symposium sponsored by ASTM Committee D.22 on sampling and analysis of atmosphere. Boulder, Colorado, 2-5 August, 1981 (ASTM Special Technical Publication No. 786). Philadelphia, American Society for Testing and Materials, 1982.

9. Preventing lead poisoning in young children. Atlanta, Georgia, Centers for Disease Control and Prevention, 2005.

10. Screening young children for lead poisoning: guidance for state and local public health officials. Atlanta, Georgia, Centers for Disease Control, 1997.
11. Needleman HL. Lead poisoning. Annual Review of Medicine, 2004, 55:209-222.

12. Jamil $\mathrm{H}$ et al. Lead absorption in battery factory workers. Journal of the Faculty of Medicine, Baghdad, 1987, 29:211-222.

13. Al-Timimi DJ et al. Lead exposure among the general population. Iraqi Medical Journal, 1988, 37:111-116.

14. Al-Timimi DJ, Jamil H, Abu-timman AK. Effect of traffic on lead absorption among children. Journal of the Faculty of Medicine, Baghdad, 1988, 30:95-103.

15. A review of literature on healthy environments for children in the Eastern Mediterranean Region. Status of childhood lead exposure. Cairo, World Health Organization Regional Office for the Eastern Mediterranean, 2003.

16. Al-Dosky AH, Al-Timimi DJ, Al-Dabbagh SA. Occupational exposure to lead in Duhok city, Kurdistan region, Iraq. Duhok Medical Journal, 2011, 5(2):76-85.

17. Sole E, Ballabriga A, Dominguez C. Lead exposure in the general population of the Metropolitan area of Barcelona: Blood levels and related factors. Science of the Total Environment, 1988, 224:19-27.

18. Binns H, Campbell C, Brown M. Interpreting and managing blood lead levels of less than $10 \mathrm{microg} / \mathrm{dL}$ in children and reduced exposure to lead: recommendations of the Centers for Disease Control and Prevention Advisory Committee on Childhood Lead Poisoning Prevention. Pediatrics, 2007, 120:1285-1298.

19. National report on human exposure to environmental chemicals. Atlanta, Georgia, Centers for Disease Control and Prevention, 2001.

20. World health report 2001. Mental health: new understanding, new hope. Geneva, World Health Organization, 2001. 